\title{
Synthesis and Characterization of Hydrotris(3-phenylpyrazolyl)borate Ligands on Low- Valent Uranium
}

Sara A. Johnson, Caleb J. Tatebe, Stephanie Gonzalez, Matthias Zeller, and Suzanne C. Bart*

\section{sbart@purdue.edu}

H. C. Brown Laboratory, Department of Chemistry, Purdue University, West Lafayette, Indiana 47907, United States

\begin{abstract}
Treating both $\mathrm{UI}_{3}(\mathrm{THF})_{4}$ and $\mathrm{UI}_{4}(\text { dioxane })_{2}$ with one equivalent of potassium hydrotris(3phenylpyrazolyl)borate, $\mathrm{KTp}^{\mathrm{Ph}}$, resulted in the formation of new low-valent uranium derivatives, $\mathrm{Tp}^{\mathrm{Ph}} \mathrm{UI}_{2}(\mathrm{THF})_{2}(\mathbf{1})$ and $\mathrm{Tp}^{\mathrm{Ph}} \mathrm{UI}_{3}$ (2), respectively. Spectroscopic characterization of these species shows that the $\mathrm{Tp}^{\mathrm{Ph}}$ ligand is 1,2-borotropically shifted, causing one phenyl group to point towards the B-H rather than the uranium center. Derivatization of these materials was possible via salt metathesis reactions, and in each case, the borotropically shifted phenyl group is maintained. Treating trivalent $\mathbf{1}$ with one equivalent of potassium phenoxide, $\mathrm{KOPh}$, afforded trivalent $\mathrm{Tp}^{\mathrm{Ph}} \mathrm{U}(\mathrm{OPh}) \mathrm{I}(\mathrm{THF})_{2}$ (1-OPh), whereas, a uranium(IV) derivative, $\mathrm{Tp}^{\mathrm{Ph}} \mathrm{UI}_{2}(\mathrm{Phpz})(\mathrm{THF})$ (2-Phpz), was synthesized by treating 2 with potassium 3-phenylpyrazolide, KPhpz. All compounds were characterized by ${ }^{1} \mathrm{H}$ and ${ }^{11} \mathrm{~B}$ NMR, infrared, and electronic absorption spectroscopies, and where possible, X-ray crystallography.
\end{abstract}

Keywords: uranium; scorpionate ligands; trivalent; tridentate; tetravalent

\section{Introduction:}

Since their discovery, scorpionate ligands have enjoyed widespread use in supporting metals of the $s$-[1-4], $p-,[5-8] d-[9-13]$ and $f$-blocks[14-17] of the Periodic Table. Their ubiquity is due in part to their steric and electronic tunability, which is easily accomplished by changing the substituted pyrazole ring. Because hydrotris(pyrazolyl)borate (Tp) ligands take up 
three metal coordination sites and are anionically charged, they are often considered to be analogous to cyclopentadienyl rings. However, unlike cyclopentadienyl rings, the steric bulk imparted by 3-pyrazole substitutions of Tp ligands generally points along the axis towards the metal rather than to the side, creating a more sterically protected environment.

When steric congestion occurs, Tp ligands have been observed to undergo a variety of rearrangements. For instance, hydrotris(3,5-dimethylpyrazolyl)borate ( $\left.\mathrm{Tp}^{*}\right)$, a pyrazole ring can dissociate from the metal center and spin around on the B-N bond, causing association of the B$\mathrm{H}$ to the new sterically accessible metal. This has been noted for the uranium(IV) imido, $\mathrm{Tp}_{2}{ }_{2} \mathrm{U}=\mathrm{NAd}$, where the large adamantyl imido substituent causes this rearrangement.[18] Steric pressure can also be relieved through a complete B-N bond scission, followed by bond formation to the other pyrazole nitrogen, known as a 1,2-borotropic shift. This is typically observed for asymmetric pyrazole rings, where one side has a bulky substituent, and the other does not, thus, there is an energetic gain to the rearrangement. This has been noted for the synthesis of hydrotris(3-mesitylpyrazolyl) borate $\left(\mathrm{Tp}^{\mathrm{Ms}}\right)$, where Jordan and co-workers found their synthesis of hafnium and zirconium complexes to experience a 1,2-borotropic shift.[19]

In previous work from our group, we have demonstrated the utility of the $\mathrm{Tp} *$ ligand to support low-valent uranium.[18,20-31] However, the steric protection of this ligand is limited due to the small size of the methyl groups. Thus, we sought to explore hydrotris(pyrazolyl)borate with 3-phenylpyrazole rings $\left(\mathrm{Tp}^{\mathrm{Ph}}\right)$, as the large size of the phenyl groups could offer additional protection for the synthesis of small terminally bonded ligands. Herein, we describe our efforts aimed at ligand metallation and characterization of low-valent $\mathrm{Tp}^{\mathrm{Ph}}$-uranium species. Spectroscopic and structural studies support a borotropically shifted pyrazole ring for both uranium(III) and uranium(IV). 


\section{Materials and Methods:}

General Considerations. All air- and moisture-sensitive manipulations were performed using standard Schlenk techniques or in an MBraun inert atmosphere drybox with an atmosphere of purified nitrogen. The MBraun drybox is equipped with a cold well designed for freezing samples in liquid nitrogen, as well as two $-35{ }^{\circ} \mathrm{C}$ freezers for cooling samples and crystallizations. Solvents for sensitive manipulations were dried and deoxygenated using literature procedures with a Seca solvent purification system.[32] Benzene- $d_{6}$ was purchased from Cambridge Isotope Laboratories, dried with molecular sieves and sodium, and degassed by three freeze-pump-thaw cycles. THF- $d_{8}$ was used as received from Cambridge Isotope Laboratories. 3-Phenyl-1H-pyrazole, trimethylamine, and phenol were purchased from Oakwood Chemical and used without further purification. Potassium phenolate (KOPh) was made by the deprotonation of phenol with benzyl potassium. $\mathrm{UI}_{3}(\mathrm{THF})_{4}[33], \mathrm{UI}_{4}(1,4-$ dioxane $)_{2}[33]$, and $\mathrm{KTp}^{\mathrm{Ph}}[9]$ were made according to literature procedures.

${ }^{1} \mathrm{H}$ NMR spectra were recorded on a Varian Inova 300 spectrometer operating at 299.992

MHz. ${ }^{11}$ B NMR spectra were recorded on a Varian Inova 300 spectrometer operating at a frequency of 96.24 MHz. ${ }^{13} \mathrm{C}$ NMR spectra were recorded on a Bruker AV500HD spectrometer equipped with a $5 \mathrm{~mm}$ BBFOZ-gradient Cryoprobe Prodigy and operating at $126 \mathrm{MHz} .{ }^{1} \mathrm{H}$ and ${ }^{13} \mathrm{C}$ chemical shifts are reported relative to the peak for $\mathrm{SiMe}_{4}$, using ${ }^{1} \mathrm{H}$ residual chemical shifts of the solvent as a secondary standard. ${ }^{11} \mathrm{~B}$ chemical shifts are reported relative to $\mathrm{BF}_{3} \cdot \mathrm{Et}_{2} \mathrm{O}$. The spectra for paramagnetic molecules were obtained using an acquisition time of $0.5 \mathrm{~s}$, thus the peak widths reported have an error of $\pm 2 \mathrm{~Hz}$. For paramagnetic molecules, the ${ }^{1} \mathrm{H}$ NMR data are reported with the chemical shift, followed by the peak width at half height in Hertz, the integration value, and, where possible, the peak assignment. Solid state infrared spectra were 
recorded using a Thermo Nicolet 6700 spectrophotometer; samples were made by crushing the solids, mixing with dry $\mathrm{KBr}$ and pressing into a pellet. Electronic absorption measurements were recorded at $294 \mathrm{~K}$ in sealed $1 \mathrm{~cm}$ quartz cuvettes with a Cary 6000i UV-vis-NIR spectrophotometer. Elemental analyses were performed by Complete Analysis Laboratories, Inc., in Parsippany, NJ or Midwest Microlab LLC in Indianapolis, IN.

Single crystals suitable for X-ray diffraction $(\mathbf{1} \times \mathbf{2}-\mathbf{P h p z}, \mathbf{1 - O P h}$ and 2-Phpz $)$ were coated with poly(isobutylene) oil in a glovebox. Crystals of 2-Phpz were transferred to the goniometer head of a Rigaku R-axis curved image plate diffractometer equipped with a MicroMax002+ high-intensity copper $\mathrm{X}$-ray source with confocal optics and examined with $\mathrm{Cu} \mathrm{K} \alpha$ radiation $(\lambda=$ $1.54184 \AA$ ). . Crystals of $\mathbf{1} \times \mathbf{2}-\mathbf{P h p z}$ and $\mathbf{1}-\mathbf{O P h}$ were transferred to the goniometer head of a Nonius KappaCCD diffractometer equipped with a graphite crystal incident beam monochromator and examined with Mo K $\alpha$ radiation $(\lambda=0.71073 \AA)$. Data were collected at low temperature. Data on the KappaCCD instrument were collected using the Nonius Collect software.[34] Data from the R-axis diffractometer were collected using the dtrek option of CrystalClear.[35] All data sets were processed using HKL3000[36] and data were corrected for absorption and scaled using Scalepack.[36] The space groups were assigned using XPREP from the Shelxtl suite of programs[37] and the structures were solved by direct methods with SHELXS[38] and refined by full matrix least squares against $F^{2}$ with all reflections using the graphical user interface ShelXle[39] for refinement program SHELXL.[40] $\mathrm{H}$ atoms attached to carbon and boron atoms were positioned geometrically and constrained to ride on their parent atoms, with carbon hydrogen bond distances of $0.95 \AA$ for and aromatic C-H, 1.00, 0.99 and 0.98 $\AA$ for aliphatic $\mathrm{C}-\mathrm{H}, \mathrm{CH}_{2}$ and $\mathrm{CH}_{3}$ moieties, respectively. Methyl $\mathrm{H}$ atoms were allowed to rotate but not to tip to best fit the experimental electron density. $\mathrm{U}_{\text {iso }}(\mathrm{H})$ values were set to a multiple of 
$\mathrm{U}_{\text {eq }}(\mathrm{C} / \mathrm{B})$ with 1.5 for $\mathrm{CH}_{3}$, and 1.2 for $\mathrm{C}-\mathrm{H}, \mathrm{CH}_{2}$ and $\mathrm{B}-\mathrm{H}$ units, respectively. Experimental details for each crystal are included in Table 2.

In the co-crystal of $\mathbf{1}$ and 2-Phpz a phenylpyrazole and a THF molecule are disordered with each other at a metal coordination site. The disorder is associated with 1:1 disorder of an ether molecule around an inversion center, and the THF/pyrazole disorder was refined as 1:1. The THF molecule was restrained to have a similar geometry as the other not disordered THF molecule in the structure. The 3-phenylpyrazole's geometry was restrained to be similar to that of one of the fragments in the tris pyrazole borate anion. Equivalent bonds in the ether molecule were restrained to be similar. $\mathrm{U}_{\mathrm{ij}}$ components of ADPs for all disordered atoms were restrained to be similar if closer than $1.7 \AA$.

In the crystal of pure 2-Phpz a THF molecule is disordered around an inversion center and induces disorder of two adjacent metal coordinated ligand moieties. The THF molecule was refined to be similar in geometry as the other not disordered THF molecule in the structure, and $\mathrm{U}_{\mathrm{ij}}$ components of ADPs were restrained to be similar if closer than $1.7 \AA$. The ligand moieties adjacent to the THF molecule were split in each two 1:1 disordered units. Both moieties of each disordered ligand were each restrained to be similar in geometry, and $\mathrm{U}_{\mathrm{ij}}$ components of ADPs were restrained to be similar if closer than $1.7 \AA$.

Preparation of KPhpz: A $20 \mathrm{~mL}$ scintillation vial was charged with $0.050 \mathrm{~g}(0.38 \mathrm{mmol})$ of benzylpotassium and $5 \mathrm{~mL}$ of THF. A second vial was charged with one equivalent 3-phenyl$1 H$-pyrazole $(0.38 \mathrm{mmol})$ and $5 \mathrm{~mL}$ of THF. The solution of 3-phenylpyrazole was added dropwise to the stirring solution of benzylpotassium. An instant color change from orange to pale yellow was observed. Solvent was removed by vacuum and the pale yellow solid was washed with pentane. A quantitative yield of KPhpz was obtained. Elemental analysis of KPhpz: calcd: 
C 59.31, H 3.87, N 15.37; found: C 58.88, H 3.93, N 15.20. ${ }^{1} \mathrm{H}$ NMR (THF- $\left.d_{8}, 25^{\circ} \mathrm{C}\right): \delta(\mathrm{ppm})=$ $6.40(\mathrm{~d}, 1 \mathrm{H}$, pyrazole- $\mathrm{CH}), 6.96(\mathrm{t}, 1 \mathrm{H}$, para- $\mathrm{CH}), 7.16(\mathrm{t}, 2 \mathrm{H}$, ortho- $\mathrm{CH}), 7.61(\mathrm{~d}, 2 \mathrm{H}$, pyrazole$\mathrm{CH}), 7.82(\mathrm{~d}, 2 \mathrm{H}$, meta-CH$) .{ }^{13} \mathrm{C}\left(\mathrm{THF}-d_{8}, 25{ }^{\circ} \mathrm{C}\right): \delta(\mathrm{ppm})=151.5,140.0,139.2,128.9,125.7$, 125.1, 100.3.

Preparation of $\mathbf{T} \mathbf{p}^{\mathrm{Ph}} \mathbf{U I}_{2}(\mathbf{T H F})_{2}$ (1): A $20 \mathrm{~mL}$ scintillation vial was charged with $\mathrm{UI}_{3}(\mathrm{THF})_{4}$ $(0.100 \mathrm{~g}, 0.110 \mathrm{mmol}), \mathrm{KTp}^{\mathrm{Ph}}(0.054 \mathrm{~g}, 0.110 \mathrm{mmol})$ and $10 \mathrm{~mL}$ THF. The slurry was stirred at room temperature for 2 hours and a color change from blue to bright purple occurred with formation of KI as a white solid. The solution was filtered over Celite and rinsed with THF. The filtrate was dried in vacuo and washed with pentane to afford a purple solid $(0.083 \mathrm{~g}, 0.077$ mmol, $71 \%$ yield). Dark purple crystals suitable for X-ray crystallography were grown from concentrated THF layered with pentane at $-35^{\circ} \mathrm{C}$. Elemental analysis of 1: calcd: C $40.86 \mathrm{H} 3.78$ N 7.33; found: C 40.08, H 4.11, N 6.68. ${ }^{1} \mathrm{H}$ NMR $\left(\mathrm{C}_{6} \mathrm{D}_{6}, 25{ }^{\circ} \mathrm{C}\right): \delta(\mathrm{ppm})=-12.51\left(3,4 \mathrm{H}, \mathrm{Tp}^{\mathrm{Ph}}-\right.$ $\mathrm{CH}), 3.73$ (105, 4H, endo $\mathrm{Tp}^{\mathrm{Ph}}$-ortho/meta-CH), 4.44 (110, 8H, THF), 5.79 (8, 4H, endo $\mathrm{Tp}^{\mathrm{Ph}}$ ortho/meta-CH $), 8.01\left(5,2 \mathrm{H}\right.$, exo $\left.\mathrm{Tp}^{\mathrm{Ph}}-\mathrm{CH}\right), 8.22\left(23,2 \mathrm{H}\right.$, endo $\mathrm{Tp}^{\mathrm{Ph}}$-para- $\left.\mathrm{CH}\right), 8.42(33,1 \mathrm{H}$, exo $\mathrm{Tp}^{\mathrm{Ph}}$-para-CH), 8.88 (8H, THF), $10.11\left(28,2 \mathrm{H}\right.$, exo $\mathrm{Tp}^{\mathrm{Ph}}$-ortho/meta-CH), $14.88(52,2 \mathrm{H}$, $\mathrm{Tp}^{\mathrm{Ph}}$-ortho/meta-CH). ${ }^{11} \mathrm{~B}$ NMR $\left(\mathrm{C}_{6} \mathrm{D}_{6}, 25^{\circ} \mathrm{C}\right): \delta(\mathrm{ppm})=20.63$. IR $(\mathrm{KBr}) v_{\mathrm{B}-\mathrm{H}}=2511 \mathrm{~cm}^{-1}$.

Preparation of $\mathbf{T} \mathbf{p}^{\mathrm{Ph}} \mathbf{U I}_{3}$ (2): A $20 \mathrm{~mL}$ scintillation vial was charged with $\mathrm{UI}_{4}(1,4$-dioxane) 2 $(0.100 \mathrm{~g}, 0.108 \mathrm{mmol}), \mathrm{KTp}^{\mathrm{Ph}}(0.052 \mathrm{~g}, 0.108 \mathrm{mmol})$, and $10 \mathrm{~mL}$ of THF. The orange slurry was stirred at room temperature for 1 hour, upon which time the color changed to bright yellow. The reaction mixture was filtered over Celite to remove KI, and dried under reduced pressure. The residue was washed with pentane $(2 \times 10 \mathrm{~mL})$ and dried under vacuum, affording a yellow powder $(0.091 \mathrm{~g}, 0.086 \mathrm{mmol}, 79 \%$ yield). Compound was not stable enough for elemental analysis. Attempts at obtaining single crystals suitable for X-ray analysis were unsuccessful. ${ }^{1} \mathrm{H}$ 
$\operatorname{NMR}\left(\mathrm{C}_{6} \mathrm{D}_{6}, 25^{\circ} \mathrm{C}\right): \delta(\mathrm{ppm})=-8.17(3), 5.76(2), 6.42(33), 6.96$ (23), 7.97 (45), $13.92(5)$,

23.25 (29), 49.09 (4), 55.77 (3), 67.01 (4), $81.72(3) .{ }^{11} \mathrm{~B}$ NMR $\left(\mathrm{C}_{6} \mathrm{D}_{6}, 25^{\circ} \mathrm{C}\right): \delta(\mathrm{ppm})=-2.65$. $\mathrm{IR}(\mathrm{KBr}) v_{\mathrm{B}-\mathrm{H}}=2490 \mathrm{~cm}^{-1}$.

Preparation of $\mathbf{T} \mathbf{p}^{\mathrm{Ph}} \mathbf{U I}(\mathbf{O P h})(\mathbf{T H F})_{2}$ (1-OPh): A $20 \mathrm{~mL}$ scintillation vial was charged with $0.050 \mathrm{~g}(0.047 \mathrm{mmol})$ of 1 and $5 \mathrm{~mL}$ of THF and cooled to $-108^{\circ} \mathrm{C}$. A second vial was charged with one equivalent of $\mathrm{KOPh}(0.006 \mathrm{~g}, 0.047 \mathrm{mmol})$ and $5 \mathrm{~mL}$ of $\mathrm{THF}$ and cooled to $-108{ }^{\circ} \mathrm{C}$. While thawing, the two solutions were mixed and stirred for 5 minutes at room temperature before being placed in a freezer at $-35{ }^{\circ} \mathrm{C}$. The reaction mixture was cooled for 30 minutes and occasionally agitated, over which time the bright purple solution darkened to deep blue. The solution was filtered over Celite to remove KI and dried in vacuo, affording a dark blue powder (0.046 g, $0.044 \mathrm{mmol}, 95 \%$ yield). Black block crystals suitable for X-ray crystallography, were grown from a concentrated THF solution layered with hexane (1:2). Compound was not stable enough for elemental analysis. ${ }^{1} \mathrm{H}$ NMR $\left(\mathrm{C}_{6} \mathrm{D}_{6}, 25^{\circ} \mathrm{C}\right): \delta(\mathrm{ppm})=-12.26$ (36), -4.96 (132), 5.07 (5), 5.53 (4), 5.84 (6), 6.14 (4), 6.89 (6), 7.29 (6), 8.40 (18), 9.87 (3), 10.41 (10), 13.80 (5), 15.06 (46), $25.38(3), 31.50(28) .{ }^{11} \mathrm{~B}$ NMR $\left(\mathrm{C}_{6} \mathrm{D}_{6}, 25^{\circ} \mathrm{C}\right): \delta(\mathrm{ppm})=-15.98 . \mathrm{IR}(\mathrm{KBr}) v_{\mathrm{B}-\mathrm{H}}=2496 \mathrm{~cm}^{-}$ 1

Alternate preparation of 1-OPh: A $20 \mathrm{~mL}$ scintillation vial was charged with $0.050 \mathrm{~g}(0.047$ mmol) of 1,6 equivalents of triethylamine $(0.279 \mathrm{mmol})$, and $5 \mathrm{~mL}$ of THF. A second vial was charged with one equivalent of phenol $(0.005 \mathrm{~g}, 0.047 \mathrm{mmol})$ and $5 \mathrm{~mL}$ of THF. Both solutions were frozen in a coldwell to $-108^{\circ} \mathrm{C}$. While thawing, the solution of phenol was added dropwise to the thawing solution of $\mathbf{1}$. The reaction was stirred at room temperature for 10 minutes until completely thawed and mixed. Following addition, the reaction mixture was placed in the freezer at $-35^{\circ} \mathrm{C}$ for two hours and agitated occasionally, causing the bright purple solution to change to 
dark blue. The reaction was filtered over Celite to remove triethylammonium iodide and the filtrate was dried under vacuum and washed with pentane to afford 1-OPh $(0.038 \mathrm{~g}, 0.037 \mathrm{mmol}$, $80 \%$ yield).

Preparation of $\mathbf{T p}^{\mathrm{Ph}} \mathbf{U I}_{\mathbf{2}}$ (3-phenylpyrazole) (2-Phpz): A $20 \mathrm{~mL}$ scintillation vial was charged with $2(0.050 \mathrm{~g}, 0.047 \mathrm{mmol})$ and $5 \mathrm{~mL}$ of THF. A second vial was charged with KPhpz $(0.010$ $\mathrm{g}, 0.047 \mathrm{mmol}$ ) and $5 \mathrm{~mL} \mathrm{THF}$. Both vials were cooled to $-35^{\circ} \mathrm{C}$; after which the $\mathrm{KPhpz}$ solution was added dropwise to 2 while stirring. The reaction mixture was placed in the freezer for 2 hours with frequent agitation. The bright orange-yellow solution slowly lightened to pale yellow. KI was filtered over Celite; crude 2-Phpz was washed with pentane $(2 \times 5 \mathrm{~mL})$ and volatiles were removed in vacuo to afford a yellow solid (0.045 g, $0.0392 \mathrm{mmol}, 71 \%$ yield). Colorless crystals suitable for X-ray crystallography were grown from a THF solution layered with pentane at $-35{ }^{\circ} \mathrm{C} . \mathrm{C}_{40} \mathrm{H}_{36} \mathrm{BI}_{2} \mathrm{~N}_{8} \mathrm{OU}$ : calcd. C 41.83, N 9.76, H 3.25; found $\mathrm{C} 41.75, \mathrm{~N} 9.59, \mathrm{H} 3.43 .{ }^{1} \mathrm{H}$ $\operatorname{NMR}\left(\mathrm{C}_{6} \mathrm{D}_{6}, 25^{\circ} \mathrm{C}\right): \delta(\mathrm{ppm})=-28.87(20),-3.77(2), 5.18(50), 5.79(5), 6.44(3), 6.95(4), 7.23$ (8), $8.00(6), 8.02(5), 10.70(8), 15.49$ (42), $15.60(9), 18.73$ (712), $22.76(10), 25.74(5) .{ }^{11} \mathrm{~B}$ $\operatorname{NMR}\left(\mathrm{C}_{6} \mathrm{D}_{6}, 25^{\circ} \mathrm{C}\right): \delta(\mathrm{ppm})=-2.10 . \mathrm{IR}(\mathrm{KBr}) v_{\mathrm{B}-\mathrm{H}}=2482 \mathrm{~cm}^{-1}$.

\section{Results and Discussion:}

Given our previous synthetic experiences with $\mathrm{Tp}^{*}$ uranium derivatives, we focused our efforts on a more sterically demanding derivative. First, a trivalent derivative was attempted by treating $\mathrm{UI}_{3}(\mathrm{THF})_{4}$ with one equivalent of $\mathrm{KTp}^{\mathrm{Ph}}$ in THF. Following workup, a purple solid was isolated, and analyzed by ${ }^{1} \mathrm{H}$ NMR spectroscopy. A paramagnetically shifted spectrum was noted, with the number of resonances suggesting asymmetry in the product. Despite this, broad resonances assignable for coordinated THF were visible at 4.44 and $8.88 \mathrm{ppm}$. One resonance

was detected by ${ }^{11} \mathrm{~B}$ NMR spectroscopy at $-20.63 \mathrm{ppm}$, which is similar to that observed for 
trivalent $\mathrm{Tp}{ }_{2} \mathrm{UF}$ at $-7.8 \mathrm{ppm}$. The IR spectrum displays a $v_{B-H}$ absorption at $2511 \mathrm{~cm}^{-1}$, which is shifted from the free ligand $\left(2408 \mathrm{~cm}^{-1}\right)$ and similar to that in $\mathrm{Tp}^{*} \mathrm{UI}_{2}(\mathrm{THF})_{2},[28]$ indicating successful metalation.

The complicated ${ }^{1} \mathrm{H}$ NMR spectrum of $\mathbf{1}$ prompted further investigation of the identity of the purple solid by means of X-ray crystallography. Diffraction quality crystals of pure $\mathbf{1}$ could not be obtained, but 1:1 co-crystals of $\mathbf{1}$ and 2-Phpz, where a phenylpyrazole displaces one of the THF molecules at uranium, allowed for the determination of the molecular structure of $\mathbf{1}$. Structural characterization revealed that a 1,2-borotropic shift had occurred, in which the boron bond migrated to the other nitrogen. The result is that one phenyl group that typically points toward the uranium center is now oriented in the opposite direction, towards the B-H bond of the scorpionate ligand. Thus, the complicated solution NMR data is rationalized by the asymmetry imparted by the borotropic shift of the pyrazolyl group, which is well precedented for sterically bulky scorpionates.[19,41-53] The geometry of the uranium is distorted trigonal prismatic. The U-N bond distances for $\mathrm{Tp}^{\mathrm{Ph}}$ in $\mathbf{1}$ are statistically identical (2.592(6), 2.603(6), 2.567(6) $\AA$ ) and within the range of what is expected based on Tp*-uranium derivatives.[20,21,24,31,54-56] The molecular structure also features a I1-U1-I2 angle of $80.96(3)^{\circ}$, which is slightly smaller than for $\mathrm{Tp}^{*} \mathrm{UI}_{2}(\mathrm{THF})_{2}$, pointing towards a more sterically hindered uranium center in $\mathbf{1}$. 


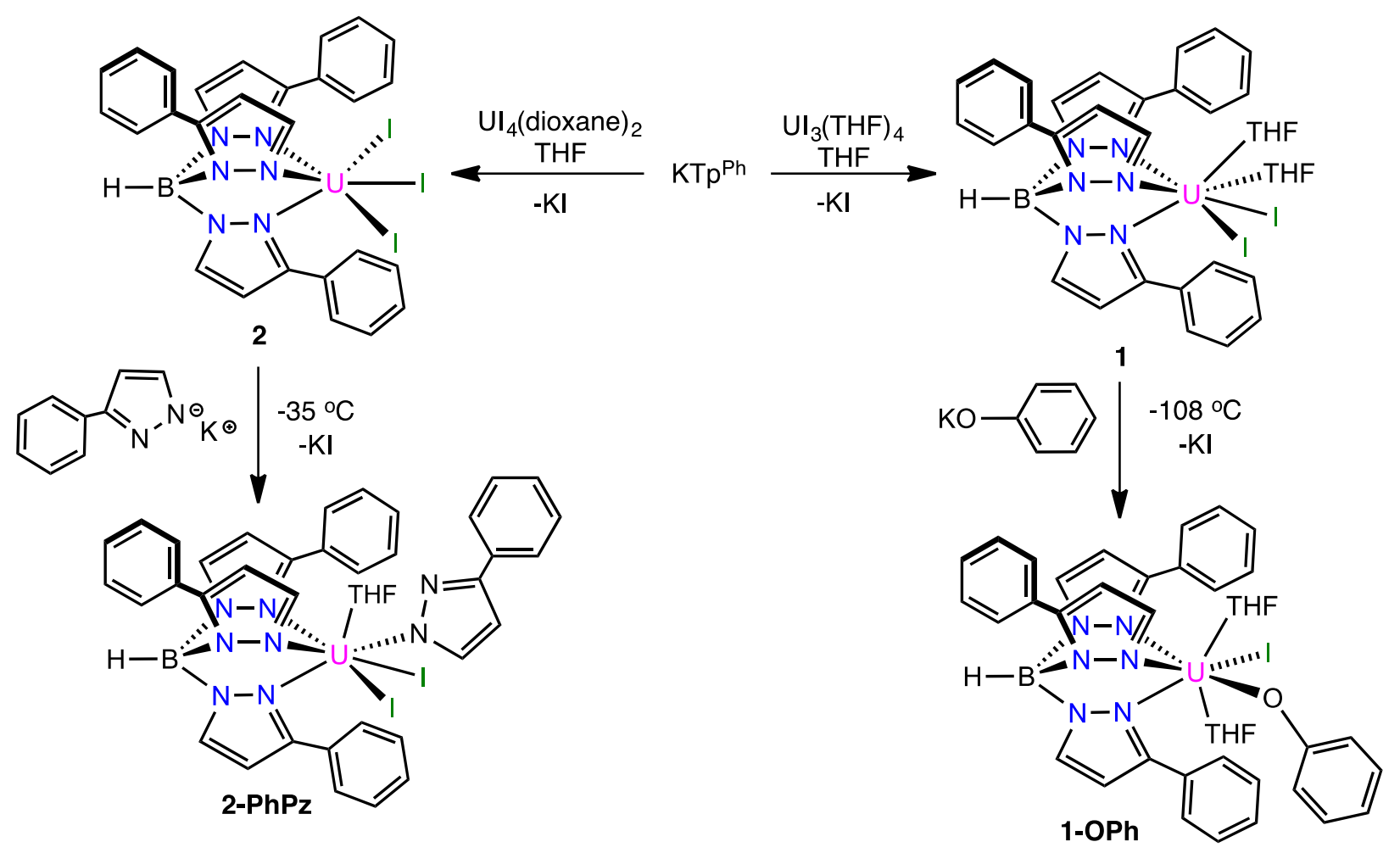

Scheme 1. Synthetic scheme for 1, 2, 1-OPh, 2-Phpz.

Formation of a uranium(IV) derivative of the $\mathrm{Tp}^{\mathrm{Ph}}$ ligand was also explored. Adding one equivalent of $\mathrm{KTp}^{\mathrm{Ph}}$ to an orange THF solution of $\mathrm{UI}_{4}(\text { dioxane })_{2}$ afforded a pale yellow solid after workup, assigned as $\mathrm{Tp}^{\mathrm{Ph}} \mathrm{UI}_{3}$ (2) (Scheme 1). Although a complicated ${ }^{1} \mathrm{H}$ NMR spectrum was noted for 2 as in the case of $\mathbf{1}$, the single resonance at $-44.22 \mathrm{ppm}$ in the ${ }^{11} \mathrm{~B}$ NMR spectrum suggested successful metalation. The upfield shift of this resonance as compared to $\mathbf{1}$ is as expected for a uranium(IV) center, and is in the range of that noted for $\mathrm{Tp}^{*}{ }_{2} \mathrm{UF}_{2}(-63.7 \mathrm{ppm}) .[20]$ The infrared spectroscopic data for 2 show a $v_{B-H}$ stretch at $2490 \mathrm{~cm}^{-1}$, which is consistent for a B-H of a scorpionate coordinated to uranium(IV), as in the case of hydrobis(3mesitylpyrazolyl)(5-mesitylpyrazolyl)borate $\left(\mathrm{Tp}^{\mathrm{Ms} *}\right) \mathrm{Tp}^{\mathrm{Ms}^{*}} \mathrm{UCl}_{3}\left(2510 \mathrm{~cm}^{-1}\right)$. Based on the similar spectroscopic features to $\mathbf{1}$ and $\mathrm{Tp}^{\mathrm{Ms}^{*}} \mathrm{UCl}_{3}$,[53] we propose the structure of $\mathbf{2}$ to contain one borotropically shifted pyrazole ring and three iodides completing the coordination sphere. There is no spectroscopic evidence for the presence of coordinated THF molecules. While $\mathbf{1}$ and 
2 are air and moisture sensitive, these compounds show excellent resilience under inert atmosphere, as both are stable at room temperature for hours and are stable for weeks when stored at $-35^{\circ} \mathrm{C}$.

In order to assess the reactivity of the $\mathrm{Tp}^{\mathrm{Ph}}$ uranium iodide compounds which feature the unusual borotropic shift, alkoxide and pyralozide derivatives were made. For trivalent 1, the phenoxide derivative was targeted to take advantage of the high oxophilicity of uranium. Treating 1 with one equivalent of potassium phenoxide caused a color change from bright purple to deep blue over thirty minutes (Scheme 1, top). After workup, to remove the KI, a blue/black solid was isolated and assigned as $\mathrm{Tp}^{\mathrm{Ph}} \mathrm{U}(\mathrm{OPh}) \mathrm{I}(\mathrm{THF})_{2}$ (1-OPh). This species can also be synthesized by the addition of phenol to $\mathbf{1}$ in the presence of triethylamine, however the removal of KI is easier than $\left[\mathrm{HNEt}_{3}\right][\mathrm{I}]$ and leads to a larger yield and cleaner product. The ${ }^{1} \mathrm{H}$ NMR spectrum shows similar asymmetry as seen with 1, 2, and 2-Phpz. The protons of the phenoxide appear (para-CH:15.06, ortho/meta-CH: 25.38, ortho/meta-CH: $31.50 \mathrm{ppm}$ ) similarly shifted as those found for $\mathrm{Tp}_{2}^{*} \mathrm{UOPh}$ (para-CH:18.35, meta-CH: 21.26, ortho-CH: $42.57 \mathrm{ppm}$ ). [23] The ${ }^{11} \mathrm{~B}$ NMR spectrum displays one resonance $(-0.85 \mathrm{ppm})$, which is consistent with trivalent $\mathrm{Tp}_{2}{ }_{2} \mathrm{UF}[20]$ and other $\mathrm{Tp}$ *-uranium (III) complexes.[31] The IR spectrum reveals an absorption at $2496 \mathrm{~cm}^{-1}$, assignable to the B-H for the coordinated ligand. Overall, 1-OPh is thermally sensitive, decomposing at room temperature over the course of a day.

In order to explore the coordination mode of $\mathrm{Tp}^{\mathrm{Ph}}$ in 1-OPh, black block crystals suitable for X-ray crystallography were grown from a concentrated THF solution layered with hexane (1:2). Analysis showed the expected seven-coordinate uranium(III) phenoxide compound, with two additional THF molecules completing the coordination sphere. The structural geometry is observed to be distorted pentagonal bipyramidal. The borotropically shifted pyrazole ring is 
maintained and is in a trans position to the aryloxide. The U-O $\mathrm{O}_{\text {aryloxide }}$ distance, $2.184(2) \AA$, and angle, $162.6(2)^{\circ}$, is on the order of other scorpionate uranium(III) aryloxide species, including Tp* ${ }_{2}$ UOMes, $\left(2.159(10) \AA, 168.2(10)^{\circ}\right)$. [53] The U-N distances are within error of those for $\mathbf{1}$, as well as trivalent $\mathrm{Tp}^{*}-\mathrm{U}$ derivatives,[20,21,24,31,54-56].

Derivatization of $\mathbf{2}$ was also explored. In this case, formation of the phenylpyrazole derivative, $\mathrm{Tp}^{\mathrm{Ph}} \mathrm{UI}_{2}$ (3-phenylpyrazole) (2-Phpz), was targeted, since a similar adduct is known for the more common $\mathrm{Tp}^{*}$-uranium system, $\mathrm{Tp}_{2}^{*} \mathrm{U}(3,5$-dimethylpyrazole).[55] Synthesis of the desired species was accomplished by treating $\mathbf{2}$ with a single equivalent of KPhpz in THF at -35 ${ }^{\circ} \mathrm{C}$ (Scheme 1). Compound 2-Phpz is stable at room temperature over several hours. Analysis by ${ }^{1}$ H NMR spectroscopy shows a highly asymmetrical spectrum featuring broad, paramagnetially shifted resonances. Once again, confirmation of the $\mathrm{Tp}^{\mathrm{Ph}}$ ligand coordinated to uranium was obtained by ${ }^{11}$ B NMR spectroscopy $(-2.10 \mathrm{ppm})$ and IR spectroscopy $\left(v_{B-H}=2482 \mathrm{~cm}^{-1}\right)$.

The solid state structure of 2-Phpz was elucidated using X-ray crystallography, following work up, colorless crystals were grown from THF layered with pentane at $-35^{\circ} \mathrm{C}$ (Figure 1 , Table 1). Refinement of the data showed the targeted $\mathrm{Tp}^{\mathrm{Ph}}$-uranium compound, with two iodide and one 3-phenylpyrazole ligands. One molecule of THF completes the coordination sphere giving the molecule a slightly distorted trigonal prismatic geometry. A disordered interstitial THF molecule imparts disorder onto the coordinated phenylpyrazole in 2-Phpz (vide supra). As for $\mathbf{1}$ and 1-OPh, the borotropically shifted phenylpyrazole ring is maintained, as in the case of the synthesis of $\mathrm{Tp}^{\mathrm{Ms}} \mathrm{U}\left[\mathrm{N}\left(\mathrm{SiMe}_{3}\right)_{2}\right] \mathrm{Cl}_{2} \cdot[53]$ 

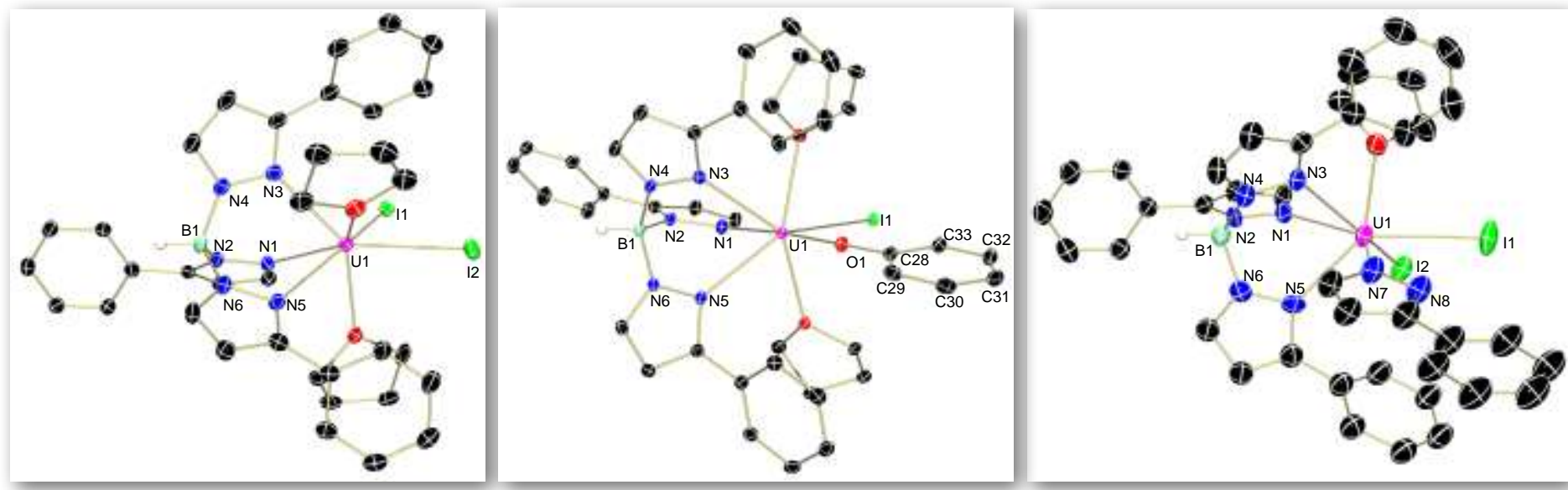

Figure 1: Molecular structures of 1 (left), 1-OPh (middle) and 2-Phpz (right), displayed with $30 \%$ probability. All disorder, selected hydrogen atoms, co-crystalized moieties and solvent molecules are omitted for clarity.

Table 1. Select bond distances of 1, 2-Phpz, and 1-OPh.

\begin{tabular}{cccc}
\hline $\begin{array}{c}\text { Bond Distances } \\
(\AA)\end{array}$ & $\mathrm{Tp}^{\mathrm{Ph}} \mathrm{UI}_{2}(\mathrm{THF})_{2}(1)$ & $\begin{array}{c}\mathrm{Tp}^{\mathrm{Ph}} \mathrm{UI}_{2}(\mathrm{Phpz})(\mathrm{THF}) \\
(2-\mathrm{Php})\end{array}$ & $\begin{array}{c}\mathrm{Tp}^{\mathrm{Ph}} \mathrm{UI}(\mathrm{OPh})(\mathrm{THF})_{2} \\
(1-\mathrm{OPh})\end{array}$ \\
\hline U1-N1 & $2.567(6)$ & $2.599(7)$ & $2.594(3)$ \\
U1-N3 & $2.603(6)$ & $2.537(8)$ & $2.654(3)$ \\
U1-N5 & $2.592(6)$ & $2.610(7)$ & $2.660(3)$ \\
U1-N5 & $\mathrm{U} 1-\mathrm{I} 1: 3.2112(13)$ & $\mathrm{U} 1-\mathrm{I} 1: 3.2100(8)$ & $\mathrm{U} 1-\mathrm{N} 7: 2.60(3)$ \\
& $\mathrm{U} 1-\mathrm{I} 2: 3.1798(11)$ & $\mathrm{U} 1-\mathrm{I} 2: 3.2014(8)$ & $\mathrm{U} 1-\mathrm{O} 1: 2.184(2)$ \\
& & & $\mathrm{U} 1-\mathrm{I} 1: 3.2574(6)$ \\
\hline
\end{tabular}

Table 2. Experimental details

For all structures: triclinic, $P \overline{1}$. Absorption was corrected for by multi-scan methods, SCALEPACK.[36] H-atom parameters were constrained.

\begin{tabular}{|c|c|c|c|}
\hline & 2-Phpz & $1-\mathrm{OPh}$ & $1 \times 2-P h p z$ \\
\hline CCDC dep. \# & 1488925 & 1488926 & 1488924 \\
\hline \multicolumn{4}{|l|}{ Crystal data } \\
\hline Chemical formula & $\begin{array}{l}2\left(\mathrm{C}_{40} \mathrm{H}_{37} \mathrm{BI}_{2} \mathrm{~N}_{8} \mathrm{OU}\right) \\
\cdot \mathrm{C}_{4} \mathrm{H}_{8} \mathrm{O}\end{array}$ & $\begin{array}{l}\mathrm{C}_{41} \mathrm{H}_{43} \mathrm{BIN}_{6} \mathrm{O}_{3} \mathrm{U} \cdot 2( \\
\left.\mathrm{C}_{4} \mathrm{H}_{8} \mathrm{O}\right)\end{array}$ & $\begin{array}{l}\mathrm{C}_{35} \mathrm{H}_{38} \mathrm{BI}_{2} \mathrm{~N}_{6} \mathrm{O}_{2} \mathrm{U} \cdot \mathrm{C} \\
{ }_{40} \mathrm{H}_{37} \mathrm{BI}_{2} \mathrm{~N}_{8} \mathrm{OU} \cdot \mathrm{C}_{4} \\
\mathrm{H}_{10} \mathrm{O}\end{array}$ \\
\hline$M_{\mathrm{r}}$ & 2368.94 & 1187.76 & 2299.89 \\
\hline
\end{tabular}




\begin{tabular}{|c|c|c|c|}
\hline Temperature (K) & 200 & 100 & 100 \\
\hline$a, b, c(\AA)$ & $\begin{array}{l}10.1939(6) \\
11.1350(7), \\
20.6212(11)\end{array}$ & $\begin{array}{l}10.7202(16) \\
13.358(3), 17.347 \\
(2)\end{array}$ & $\begin{array}{l}9.938(2), 10.961 \\
(2), 20.389(4)\end{array}$ \\
\hline$\alpha, \beta, \gamma\left(^{\circ}\right)$ & $\begin{array}{l}103.257(4), 92.522 \\
(4), 110.858(5)\end{array}$ & $\begin{array}{l}93.094(6), 91.403 \\
(5), 105.086(9)\end{array}$ & $\begin{array}{l}100.04(3), 94.71 \\
(3), 109.75(3)\end{array}$ \\
\hline$V\left(\AA^{3}\right)$ & $2108.6(2)$ & $2392.9(8)$ & $2034.3(8)$ \\
\hline$Z$ & 1 & 2 & 1 \\
\hline Radiation type & $\mathrm{Cu} K \alpha$ & Mo $K \alpha$ & Mo $K \alpha$ \\
\hline$\mu\left(\mathrm{mm}^{-1}\right)$ & 22.68 & 4.09 & 5.55 \\
\hline Crystal shape & Chip & Block & Plate \\
\hline Colour & Purple & Black & Purple \\
\hline Crystal size $(\mathrm{mm})$ & $0.20 \times 0.10 \times 0.05$ & $0.45 \times 0.31 \times 0.27$ & $0.45 \times 0.25 \times 0.07$ \\
\hline \multicolumn{4}{|l|}{ Data collection } \\
\hline Diffractometer & $\begin{array}{l}\text { Rigaku Rapid II } \\
\text { curved image plate } \\
\text { diffractometer }\end{array}$ & $\begin{array}{l}\text { Nonius Kappa } \\
\text { CCD } \\
\text { diffractometer }\end{array}$ & $\begin{array}{l}\text { Nonius Kappa } \\
\text { CCD } \\
\text { diffractometer }\end{array}$ \\
\hline$T_{\min }, T_{\max }$ & $0.032,0.322$ & $0.175,0.405$ & $0.233,0.697$ \\
\hline $\begin{array}{l}\text { No. of measured, } \\
\text { independent and } \\
\text { observed }[I> \\
2 \square(I)] \text { reflections }\end{array}$ & $7349,7349,6203$ & $\begin{array}{l}50782,12119 \\
10688\end{array}$ & $23790,9776,7655$ \\
\hline$R_{\text {int }}$ & 0.077 & 0.035 & 0.054 \\
\hline \multicolumn{4}{|l|}{ Refinement } \\
\hline $\begin{array}{l}R\left[F^{2}>2 \square\left(F^{2}\right)\right], \\
w R\left(F^{2}\right), S\end{array}$ & $0.049,0.130,1.10$ & $0.028,0.060,1.09$ & $0.053,0.146,1.04$ \\
\hline No. of reflections & 7349 & 12119 & 9776 \\
\hline No. of parameters & 706 & 569 & 572 \\
\hline \multirow[t]{2}{*}{ No. of restraints } & 755 & 0 & 303 \\
\hline & $\begin{array}{l}w=1 /\left[\sigma^{2}\left(F_{\mathrm{o}}^{2}\right)+\right. \\
(0.0544 P)^{2}+ \\
18.1672 P] \\
\text { where } P=\left(F_{\mathrm{o}}^{2}+\right. \\
\left.2 F_{\mathrm{c}}^{2}\right) / 3\end{array}$ & $\begin{array}{l}w=1 /\left[\sigma^{2}\left(F_{\mathrm{o}}^{2}\right)+\right. \\
7.8802 P] \\
\text { where } P=\left(F_{\mathrm{o}}{ }^{2}+\right. \\
\left.2 F_{\mathrm{c}}^{2}\right) / 3\end{array}$ & $\begin{array}{l}w=1 /\left[\sigma^{2}\left(F_{\mathrm{o}}{ }^{2}\right)+\right. \\
(0.0777 P)^{2}+ \\
9.8252 P] \\
\text { where } P=\left(F_{\mathrm{o}}{ }^{2}+\right. \\
\left.2 F_{\mathrm{c}}{ }^{2}\right) / 3\end{array}$ \\
\hline
\end{tabular}


Computer programs: CrystalClear-SM Expert 2.1 b32[35], Nonius Collect[34], HKL-3000 [36], SHELXS97[38], SHELXL2014/7,[40] SHELXLE Rev714[39], SHELXLE Rev761.[39]

To gain insight into the electronic structures of the new $\mathrm{Tp}^{\mathrm{Ph}}$ family of compounds, 1, 1OPh, 2, and 2-Phpz, electronic absorption spectroscopy was employed. Data for all compounds were recorded from 300 to $1800 \mathrm{~nm}$ in THF at ambient temperature (Figure 2). For 1 and 1OPh, the visible region shows weak color-producing bands at $526 \mathrm{~nm}\left(119 \mathrm{M}^{-1} \mathrm{~cm}^{-1}\right)$ and $505 \mathrm{~nm}$ (46 $\mathrm{M}^{-1} \mathrm{~cm}^{-1}$ ), respectively. The near-infrared region displays weak and poorly defined $f-f$ transitions for $\mathbf{1}$ and $\mathbf{1 - O P h}$, which has been seen with previously reported uranium (III) complexes.[20,23,26-28,30,31] In contrast, the visible region for $\mathbf{2}$ and 2-Phpz displays broad, weak absorptions as expected for uranium(IV) species, similar to yellow $\mathrm{Tp}^{*}{ }_{2} \mathrm{U}\left(\eta^{2}-\mathrm{S}_{2}\right)$. [29] The near-infrared region for $\mathbf{2}$ and $\mathbf{2 - P h p z}$ shows sharp, weak $f-f$ transitions indicative of uranium (IV) ions.[18]

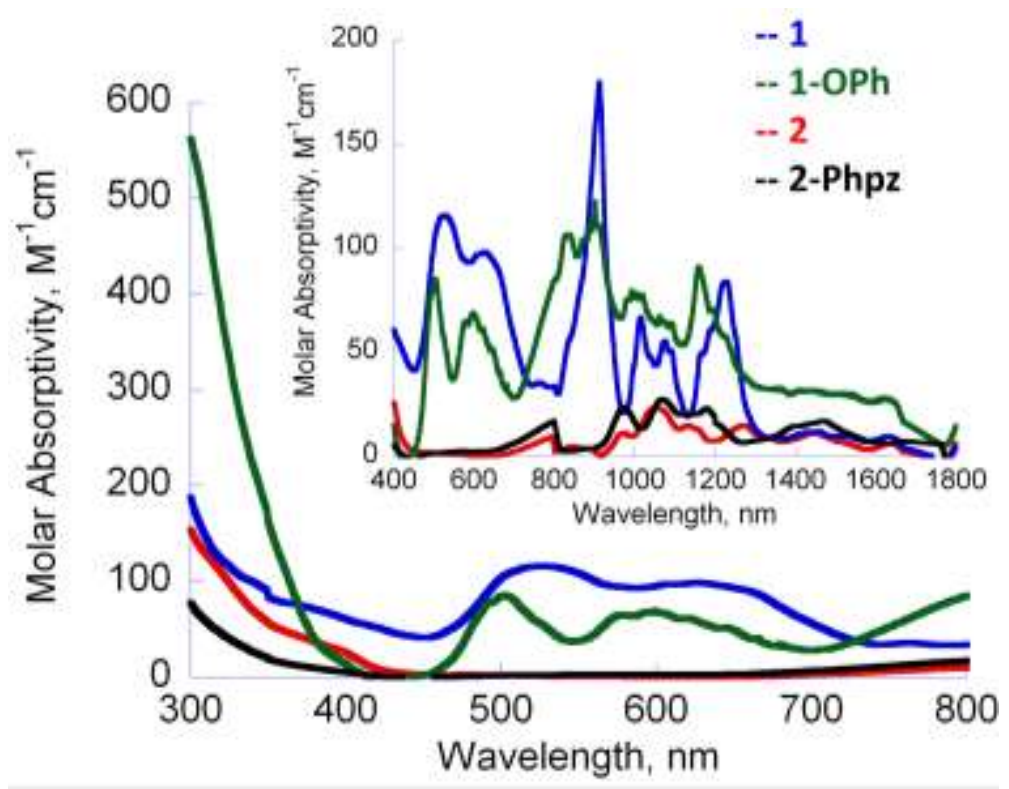

Figure 2: Electronic absorption spectra of 1, 2, 1-OPh, 2-Phpz recorded from 300 to $1800 \mathrm{~nm}$ in THF at ambient temperature. 


\section{Conclusions:}

In summary, we have synthesized uranium complexes bearing the $\mathrm{Tp}^{\mathrm{Ph}}$ scorpionate ligand. Treating these ligands with $\mathrm{UI}_{3}(\mathrm{THF})_{4}$ and $\mathrm{UI}_{4}(1,4 \text {-dioxanes })_{2}$ salts resulted in metalation and a simultaneous ligand isomerization through a 1,2-borotropic shift. Further derivatization was possible via salt metathesis, and in each case, the borotropically shifted pyrazole group was maintained. All oxidation states were maintained throughout the course of the study, with no unwanted redox chemistry occurring. The new uranium species presented here expand upon the family of scorpionate uranium compounds previously known. These unique species can adjust the steric environment of the uranium center by displacement of the phenyl rings from the coordination sphere.

\section{References:}

[1] O. Michel, H.M. Dietrich, R. Litlabø, K.W. Törnroos, C. Maichle-Mössmer, R. Anwander, Organometallics 31 (2012) 3119-3127.

[2] M.H. Chisholm, N.W. Eilerts, J.C. Huffman, S.S. Iyer, M. Pacold, K. Phomphrai, J. Am. Chem. Soc. 122 (2000) 11845-11854. 
[3] Y. Sohrin, H. Kokusen, S. Kihara, M. Matsui, Y. Kushi, M. Shiro, J. Am. Chem. Soc. 115 (1993) 4128-4136.

[4] R. Han, G. Parkin, Inorg. Chem. 31 (1992) 983-988.

[5] C.A. Dodds, A.R. Kennedy, J. Reglinski, M.D. Spicer, Inorg. Chem. 43 (2004) 394-395.

[6] Z. Ciunik, T. Ruman, M. Lukasiewicz, S. Wolowiec, J. Mol. Struct. 690 (2004) 175-180.

[7] A. Frazer, B. Piggott, M.B. Hursthouse, M. Mazid, J. Am. Chem. Soc. 116 (1994) $4127-$ 4128.

[8] G. Ferguson, M.C. Jennings, F.J. Lalor, C. Shanahan, Acta Crystallogr., Sect. C 47 (1991) 2079-2082.

[9] D.M. Eichhorn, W.H. Armstrong, Inorg. Chem. 29 (1990) 3607-3612.

[10] A. Dehestani, A. Wu, R. Hayoun, W. Kaminsky, J.M. Mayer, Inorg. Chim. Acta 362 (2009) 4534-4538.

[11] K. Mashima, T. Oshiki, K. Tani, Organometallics 16 (1997) 2760-2762.

[12] K. Michiue, T. Oshiki, K. Takai, M. Mitani, T. Fujita, Organometallics 28 (2009) 64506457.

[13] A. Kremer-Aach, W. Kläui, R. Bell, A. Strerath, H. Wunderlich, D. Mootz, Inorg. Chem. 36 (1997) 1552-1563.

[14] J. Cheng, M.J. Ferguson, J. Takats, J. Am. Chem. Soc. 132 (2010) 2-3.

[15] D. Schädle, C. Maichle-Mössmer, C. Schädle, R. Anwander, Chem.-Eur. J. 21 (2015) $662-670$.

[16] J.L. Galler, S. Goodchild, J. Gould, R. McDonald, A. Sella, Polyhedron 23 (2004) 253262.

[17] A.C. Hillier, Zhang, G.H. Maunder, S.Y. Liu, T.A. Eberspacher, M. V. Metz, R. 
McDonald, Â. Domingos, N. Marques, V.W. Day, A. Sella, J. Takats, Inorg. Chem. 40 (2001) 5106-5116.

[18] E.M. Matson, M.G. Crestani, P.E. Fanwick, S.C. Bart, Dalton Trans. 41 (2012) 7952.

[19] K. Michiue, R.F. Jordan, Organometallics 23 (2004) 460-470.

[20] C.L. Clark, J.J. Lockhart, P.E. Fanwick, S.C. Bart, Chem. Commun. 51 (2015) 1408414087.

[21] S.J. Kraft, P.E. Fanwick, S.C. Bart, Inorg. Chem. 49 (2010) 1103-1110.

[22] S.J. Kraft, J.R. Walensky, P.E. Fanwick, M.B. Hall, S.C. Bart, Inorg. Chem. 49 (2010) $7620-7622$.

[23] E.M. Matson, A.T. Breshears, J.J. Kiernicki, B.S. Newell, P.E. Fanwick, M.P. Shores, J.R. Walensky, S.C. Bart, Inorg. Chem. 53 (2014) 12977-12985.

[24] E.M. Matson, P.E. Fanwick, S.C. Bart, Eur. J. Inorg. Chem. 2 (2012) 5471-5478.

[25] E.M. Matson, P.E. Fanwick, S.C. Bart, Organometallics 30 (2011) 5753-5762.

[26] E.M. Matson, W.P. Forrest, P.E. Fanwick, S.C. Bart, J. Am. Chem. Soc. 133 (2011) 49484954.

[27] E.M. Matson, W.P. Forrest, P.E. Fanwick, S.C. Bart, Organometallics 32 (2013) 14841492.

[28] E.M. Matson, W.P. Forrest, P.E. Fanwick, S.C. Bart, Organometallics 31 (2012) 44674473.

[29] E.M. Matson, M.D. Goshert, J.J. Kiernicki, B.S. Newell, P.E. Fanwick, M.P. Shores, J.R. Walensky, S.C. Bart, Chem.-Eur. J. 19 (2013) 16176-16180.

[30] E.M. Matson, J.J. Kiernicki, N.H. Anderson, P.E. Fanwick, S.C. Bart, Dalton Trans. 43 (2014) 17885-17888. 
[31] E.M. Matson, J.J. Kiernicki, P.E. Fanwick, S.C. Bart, Eur. J. Inorg. Chem. 2016 (2016) $2527-2533$.

[32] A.B. Pangborn, M. a. Giardello, R.H. Grubbs, R.K. Rosen, F.J. Timmers, Organometallics 15 (1996) 1518-1520.

[33] M.J. Monreal, R.K. Thomson, T. Cantat, N.E. Travia, B.L. Scott, J.L. Kiplinger, Organometallics 30 (2011) 2031-2038.

[34] Nonius, (1998).

[35] Rigaku Corp., (2014).

[36] Z. Otwinowski, W. Minor, in:, Methods Enzymol., 1997, pp. 307-326.

[37] Bruker Advanced X-ray Solutions, (2003).

[38] G.M. Sheldrick, Acta Crystallogr., Sect. A 64 (2008) 112-122.

[39] C.B. Hübschle, G.M. Sheldrick, B. Dittrich, J. Appl. Crystallogr. 44 (2011) 1281-1284.

[40] G.M. Sheldrick, Acta Crystallogr., Sect. C 71 (2015) 3-8.

[41] M. Cano, J. V. Heras, C.J. Jones, J.A. McCleverty, S. Trofimenko, Polyhedron 9 (1990) 619-621.

[42] M.H. Chisholm, N.W. Eilerts, J.C. Huffman, Inorg. Chem. 35 (1996) 445-450.

[43] P. Cui, Y. Chen, M. V. Borzov, Dalton Trans. 39 (2010) 6886.

[44] L.R. Kadel, J.R. Bullinger, R.R. Baum, C.E. Moore, D.L. Tierney, D.M. Eichhorn, Eur. J. Inorg. Chem. 2016 (2016) 2543-2551.

[45] M. Kumar, E.T. Papish, M. Zeller, A.D. Hunter, Dalton Trans. 40 (2011) 7517.

[46] F.A. Kunrath, R.F. de Souza, O.L. Casagrande, N.R. Brooks, V.G. Young, Organometallics 22 (2003) 4739-4743.

[47] D.D. LeCloux, M.C. Keyes, M. Osawa, V. Reynolds, W.B. Tolman, Inorg. Chem. 33 
(1994) 6361-6368.

[48] L. Maria, Â. Domingos, I. Santos, Inorg. Chem. 42 (2003) 3323-3330.

[49] N. Romero, L. Vendier, C. Dinoi, M. Etienne, Dalton Trans. 43 (2014) 10114.

[50] T. Ruman, Z. Ciunik, S. Wołowiec, Eur. J. Inorg. Chem. 2003 (2003) 2475-2485.

[51] S. Trofimenko, J.C. Calabrese, P.J. Domaille, J.S. Thompson, Inorg. Chem. 28 (1989) $1091-1101$.

[52] J.M. White, V.W.L. Ng, D.C. Clarke, P.D. Smith, M.K. Taylor, C.G. Young, Inorg. Chim. Acta 362 (2009) 4570-4577.

[53] M. Silva, Â. Domingos, A. Pires de Matos, N. Marques, S. Trofimenko, J. Chem. Soc., Dalton Trans. (2000) 4628-4634.

[54] Â. Domingos, N. Marques, A.P. De Matos, I. Santos, M. Silva, Polyhedron 11 (1992) 2021-2025.

[55] M.A. Antunes, Â. Domingos, I.C. Santos, N. Marques, J. Takats, Polyhedron 24 (2005) $3038-3045$.

[56] M.A. Antunes, G.M. Ferrence, Â. Domingos, R. McDonald, C.J. Burns, J. Takats, N. Marques, Inorg. Chem. 43 (2004) 6640-6643. 